\title{
VEINTICINCO AÑOS DE RELACIÓN FIDUCIARIA ENTRE LAS CORTES \\ GENERALES Y EL GOBIERNO
}

\author{
ESTHER GONZÁLEZ HERNÁNDEZ \\ Profesora de Derecho Constitucional \\ Universidad Rey Juan Carlos
}




\title{
VEINTICINCO AÑOS \\ DE RELACIÓN FIDUCIARIA ENTRE LAS CORTES \\ GENERALES Y EL GOBIERNO
}

POR

\author{
ESTHER GONZÁLEZ HERNÁNDEZ \\ Profesora de Derecho Constitucional \\ Universidad Rey Juan Carlos
}

Decía Adolfo Posada en su Estudio sobre régimen parlamentario en España que «examinados los Parlamentos españoles, tienen un pecado de origen verdaderamente imborrable. No hay Jordán que los purifique". En las últimas décadas, muchas han sido las críticas sobre la institución parlamentaria centradas fundamentalmente su progresiva minusvalorización como órgano de decisión estatal. No era imaginable que al reconocimiento del sufragio universal siguiese tal desprestigio de la institución parlamentaria.

A diferencia de lo que ocurre con el Poder Legislativo, el Poder Ejecutivo sociológicamente es percibido como el verdadero órgano de impulso político, a pesar de que éste ocupe una posición constitucional subordinada al Parlamento, fácilmente constatable por la significativa menor atención que la Constitución le presta. Los Parlamentos actuales encuentran verdaderas dificultades para frenar el ascenso imparable de un Poder Ejecutivo que se resiste a ser un "mero comisionado ejecutor» de una política decidida previamente en la Asamblea.

Nuestra Norma Fundamental acoge la Monarquía parlamentaria como forma política del Estado español. Al margen de las recurrentes 
discusiones sobre la singular redacción de este precepto, el Texto de 1978 establece que el Gobierno necesita disfrutar ineludiblemente de la confianza del Parlamento desde el mismo momento en que se produce su nombramiento y a lo largo del ejercicio posterior de su función gubernamental (González-Trevijano, La cuestión de confianza, pág. 1). Por tanto, la Constitución española, por un lado, mantiene punto por punto la configuración decimonónica del régimen parlamentario, $y$, por otro, asume la tendencia del constitucionalismo de posguerra de constitucionalizar prácticas que antaño no eran más que convenciones, usos o costumbres parlamentarias.

El primer ejemplo histórico de un sistema parlamentario de gobierno es el régimen británico que desde hace ya varios siglos alumbró incipientes manifestaciones de sus elementos esenciales ${ }^{1}$. Quizá por este motivo, o tal vez por la idiosincrasia propia de su sistema constitucional, el parlamentarismo inglés es el régimen parlamentario por excelencia. En el Reino Unido, se entiende que el Primer Ministro

1 Durante los tiempos del Parlamento Largo, se expidió por la Cámara de los Comunes una Resolución, la Grand Remonstrance, el 22 de noviembre de 1641, en que se solicitaba del Rey que éste empleara Consejeros, Ministros y Embajadores que disfrutaran de la confianza del Parlamento. Más adelante, con la Glorious Revolutión y el Bill of Rights conllevaron la pérdida por parte de Guillermo de Orange del derecho de suspender y dispensar la ejecución de las leyes votadas por el Parlamento como consecuencia de la indiferencia por los asuntos políticos de los miembros de la Casa de Hanoover, cobraron fuerza los factores que favorecieron la aparición del Gabinete británico. En cambio, hubo que esperar algún tiempo más para que surgiese el principio de responsabilidad solidaria del Gobierno. Concretamente, en el año 1778, Lord North, Primer Ministro de Jorge III, define como principios del Gobierno británico tanto la confianza parlamentaria como la responsabilidad solidaria del Ejecutivo. El propio Lord North tendría ocasión de llevar a la práctica dicha declaración de principios el día 20 de marzo de 1782, fecha en la que se produjo la caída conjunta de los miembros de su Gabinete. Sin embargo, debe señalarse que la gestación de la responsabilidad política se enmarca en un proceso paulatino que había empezado mucho antes. Durante el largo Gobierno Walpole (1720-1742) hubo varios intentos de organizar una oposición capaz de derrocarle, pero hasta el siguiente Parlamento no fue lo suficientemente compacta para librar la batalla que le llevase a su cese. En 1739, Walpole gobernaba pese a una fuerte oposición parlamentaria, que alcanzó su punto álgido el 13 de febrero de 1741 , al presentarse diversas mociones «para la remoción de Walpole y de los consejeros de su Majestad para siempre», que fueron derrotadas. Tras esto, se disolvió el Parlamento y se convocaron nuevas elecciones. La nueva mayoría era contraria a Walpole, y los días 28 de enero y 2 de febrero de 1742, el Primer Ministro perdió dos votaciones que le obligaron a dimitir al constatar que una parte de los Whigs, encabezados por William Pitt se habian aliado contra él, y que, en consecuencia, no contaba con la confianza del Parlamento. 
designado por la Reina dispone de la confianza parlamentaria mientras no se demuestre lo contrario. Pero este dato no es el que le hace ser un sistema parlamentario puro, ni siquiera el hecho de que sea resultado de una convención constitucional, consecuencia lógica de la inexistencia de una Constitución escrita, sino la convicción conformada a lo largo de los siglos de la superioridad del Parlamento, verdadero secreto de la Constitución británica. De modo, que el Gabinete existe en tanto en cuanto lo requiere el Parlamento como especie de "comisionado ejecutivo" del Soberano político. De ahí la conocida expresión del "executive branches of government". Dicho de otro modo, el Gobierno define libremente su política, pero no la puede llevar a feliz término, si no goza de la aprobación del Parlamento. Por ello, la confianza parlamentaria asegura que el Legislativo no se verá entera e indefectiblemente en manos del Ejecutivo.

La extensión del parlamentarismo británico en el continente enfatizó su carácter democrático desde el momento en que el Parlamento gozaba de una más fuerte legitimidad que el Ejecutivo monárquico, pues era el órgano de representación popular. El término «parlamentarismo" designaba, por tanto, un tipo de Estado influido decisivamente por la representación del pueblo en su "Parlamento". Era una forma de lucha contra la Monarquía del Ancien Régime que conectaba con las corrientes más democráticas. Sin embargo, la palabra con el tiempo pasó a representar un tipo específico de Ejecutivo.

Sobre el papel, un gobierno parlamentario denota una clara superioridad del Parlamento sobre un Gabinete que actúa en tanto en cuanto aquél lo permite a través de la institución de la fiducia. De este presupuesto básico deriva la segunda característica de los sistemas parlamentarios: el control permanente del Legislativo sobre su «brazo ejecutivo" que, incluso, podrá suponer su cese por el Soberano representado en las "Dos Casas del Parlamento". En palabras de Schmitt "la exigencia de que el Parlamento controle al Gobierno y ejerza su influencia en la designación de los ministros presupone dicha fe» (Sobre el parlamentarismo, pág. 41).

No obstante, es a lo largo del siglo XIX cuando el parlamentarismo británico desarrolla el mecanismo esencial que permite articular las necesarias relaciones entre Parlamento y Ejecutivo: el principio de confianza de la Cámara de los Comunes en el Gobierno. Es más, a principios de este siglo las referencias a la confianza parlamentaria comienzan a ser frecuentes en el lenguaje político. Concretamente en 1841 Robert Peel expresó ante el Parlamento que: «si el Gobierno de su Majestad no posee la confianza suficiente en la Cámara de los 
Comunes para permitirle llevar a cabo las medidas que juzgue de esencial importancia para el bienestar público, su continuidad en el poder bajo tales circunstancias está en desacuerdo con el espíritu de la Constitución».

La presencia de dicha relación fiduciaria entre el Parlamento y el Gobierno es imprescindible en los sistemas parlamentarios de gobierno, pues garantiza y permite un cauce adecuado de colaboración entre Legislativo y Ejecutivo, así como una mutua relación de dependencia entre ambos. Así lo creían Walter Bagehot y el barón de Montesquieu. Para el primero se trataba de una estrecha unión, casi completa "fusión" de los poderes Ejecutivo y Legislativo (The English Constitution, pág. 9). Para el segundo, en un régimen parlamentario es necesario que se establezcan relaciones permanentes entre el Poder Ejecutivo $y$ el Poder Legislativo, porque "como por el movimiento necesario de las cosas, están obligados a moverse, se verán forzados a hacerlo de común acuerdo" (Del Espiritu de las leyes, pág. 113).

Dicha colaboración terminó por cristalizar en una serie de mecanismos parlamentarios, en principio, y constitucionales después, que expresan los elementos sustanciales a esa relación Legislativo-Ejecutivo. Se trata, por consiguiente, de una relación que comienza con la investidura en el Parlamento por la que se otorga la confianza al Gabinete, que sigue su curso en el control parlamentario, y finaliza con la disolución anticipada de las Cámaras, el rechazo de la cuestión de confianza, la aprobación de una moción de censura, o cuando se hubiese cumplido el término para el que la confianza fue concedida.

La constatación de que un Gobierno disfruta o no de la confianza del Parlamento es la pieza que convierte un sistema de gobierno en parlamentario. La relación fiduciaria es, por tanto, la "razón" de ser y existir de esta forma de gobierno, es decir, la visualización del respaldo de las Cámaras de que debe gozar en todo momento el Gabinete. No hace falta insistir más en este punto: sin confianza parlamentaria, haya o no mecanismo constitucional que la formalice, no es posible hablar de gobierno parlamentario.

La admiración que este sistema despertó entre los liberales fue tal, que la mayoría de los Estados europeos lo adoptaron como sistema esencialmente democrático que se oponía a la Monarquía absoluta, y se perpetuó en el tiempo aunque con algunas adaptaciones fruto de una evolución, que terminó por cristalizar en formas extremadamente rígidas: los sistemas de parlamentarismo racionalizado. Un número significativo de los modernos Estados de Derecho se han estructurado en la actualidad de acuerdo con este modelo de dis- 
tribución del poder, que se ha convertido de esta suerte, en lo que podríamos denominar, a semejanza del Derecho civil, el "régimen de Derecho Común" (González-Trevijano, págs. 3 y 4). A tal fin lo incluyeron en el seno de sus Textos fundamentales como si se tratase de seguir los dictados de una "moda universal" a diferencia de otras Constituciones que no consideraron conveniente consagrarlo en la Norma Suprema del Estado.

Sin embargo, resulta imprescindible perfilar en qué consiste este vínculo fiduciario entre Asamblea legislativa y Gobierno, pues al margen de otros elementos tradicionalmente considerados esenciales al régimen parlamentario, la manifestación de la confianza parlamentaria es su médula espinal.

El término confianza no es unívoco, pues son muchas sus acepciones en el lenguaje coloquial. Según el Diccionario de la Real Academia, por "confianza" debe entenderse: esperanza firme que se tiene de alguien o algo, seguridad que alguien tiene en sí mismo, ánimo, aliento, vigor para obrar... Por su parte, según el "María Moliner" el término "confiar" puede referirse a esperar suponer alguien para su tranquilidad que tendrá cierta cosa o que esa cosa será suficiente, o dar o dejar al cuidado de cierta cosa a alguien o algo determinado.

En su versión parlamentaria la confianza que se otorga y, por tanto, incide en la formación del Gobierno se correspondería mejor con esta última acepción. Demostrada la imposibilidad del Parlamento de asumir directamente el gobierno de la Nación, se imponía su encargo a otro sujeto. Se trata de una fórmula de superación de la democracia clásica de las Ciudades-Estado de la antigüedad. Como no todos los miembros de la comunidad política podían decidir directamente sobre los asuntos de la rex pubblica, parecía lógico servirse de una comisión electa constituida por personas "de confianza", esto es, el Parlamento. Es así como se genera la "conocida escala: el parlamento es una comisión del pueblo y el gobierno una comisión del parlamento" (Schmitt, pág. 42). Caracterizaciones del Gabinete como "comité del Parlamento" (Carré de Malberg, Contribution a la Théorie Générale de I'État, pág. 71 y ss) o "agente colocado bajo la autoridad y control de los órganos de representación" (Duguit, Traité de Droit constitutionnel, pág. 243) eran frecuentes en el constitucionalismo de preguerras, lo que naturalmente suponía la afirmación de la superior legitimidad de la Asamblea.

Sin embargo, con la extensión del derecho de sufragio y la reafirmación del ideal democrático el trámite de la confianza de la Asamblea comenzó a ser explicado como un desdoblamiento o dualidad en 
el proceso de elección del Ejecutivo. La elección de las Cámaras sería una primera concreción de la orientación política que prefiere la mayoría y, a través de la fiducia, se establecería definitivamente el encargado de su desarrollo ejecutivo. Se consigue, por tanto, conectar la relación fiduciaria con las reglas típicas de la representación política, porque la confianza en el Gobierno funciona igual que las elecciones frente al mandato representativo, es decir, la confianza que se deposita en los representantes parlamentarios determina también el principio y el final de su mandato. Es, por tanto, una materialización de los anhelos del pueblo que delega en unas personas que deberán ejercer su autoridad frente a un comisionado que debe acatar los deseos del pueblo. El concepto de confianza deviene, por tanto, imprescindible para la validez del mandato representativo, pues a través de ella el pueblo da el consentimiento para que sus representantes ejerciten el poder. Es éste el momento de reafirmación del término "confianza" (trust), que no "delegación". El Gabinete deja de ser un mero "delegado parlamentario", porque ello podría degenerar fácilmente en un peligroso predominio de la Asamblea. Estamos, por tanto, ante la versión opuesta del "parlamentarismo condicionado" en expresión de Sánchez Agesta (El sistema político de la Constitución española de 1978, pág. 256).

Esto es propio de las actuales democracias indirectas o mediatizadas en que "la decisión del electorado actúa únicamente a la manera de filtro que selecciona y determina la parte alícuota con que cada fuerza va a contribuir a la definición de la política y a la composición del equipo encargado de gestionar la fase de su ejecución" (Revenga Sánchez, La formación del Gobierno en la Constitución español de 1978, pág. 71).

Por tanto, la idea de parlamentarismo aparece como una forma de gobierno esencialmente vertical precisamente por dicha relación de "confianza": Pueblo-Parlamento-Gobierno, en línea ascendente. Verticalidad que se puede extender también en el seno del propio Gabinete, pues el Parlamento puede otorgar su confianza únicamente al candidato que se le presenta en el momento de la investidura y éste, a su vez, confía en los miembros que propone al Jefe del Estado como parte de su equipo de gobierno.

Sin embargo, dicha fiducia, una vez otorgada se podrá convertir en "desconfianza" a medida que se vaya diluyendo la tranquilidad en que esa persona, ese conjunto de personas que es el Gobierno, no tenga éxito en la misión que se le encomendó. En este momento, se convierte en una confianza negativa al pasar al estadio posterior de la exigencia de responsabilidad política. Todo representante está obligado 
a responder de la gestión que realizó de aquello que se le encomendó. Se trata de una "confianza vigilante», es decir, de control por el Parlamento de la actuación del Gabinete en el que se confió el gobierno de la Nación, que puede determinar su destitución por no ajustarse a lo que de él se esperaba. Decía con razón Hauriou, que en un gobierno parlamentario "se establece una colaboración continua entre el Poder Ejecutivo y el Poder Legislativo, por intermediación de un órgano ejecutivo que es el Consejo de Ministros que comparte con el Jefe del Estado la dirección del gobierno, pero que no puede gobernar sino asegurándose la confianza continua del Parlamento, ante el cual es políticamente responsable" (Principios de Derecho Público y Constitucional, pág. 390).

Si desde un punto de vista estructural o procedimental la confianza parlamentaria se acopla perfectamente a la lógica de la verticalidad, en el juego político es una institución principalmente horizontal por la cual el Gobierno, en cuanto emanación de la mayoría de la Cámara, se halla ligado por un vínculo fiduciario que, de romperse, da lugar a su remoción.

La concesión de la fiducia parlamentaria incluye tres contenidos: uno positivo, otro condicionante y un tercero que puede devenir en negativo. El positivo, permite la formación de Gobierno a través del otorgamiento de la confianza de muy diversos modos: un Jefe del Estado media para la formación del Gabinete ministerial entre los diversos grupos parlamentarios, una investidura otorgada directamente por el Cuerpo electoral, o la designación por el Jefe del Estado del leader del partido que ha alcanzado la mayoría parlamentaria, sin voto de investidura expreso (parlamentarismo negativo). El criterio condicionante supone una situación de constante presión parlamentaria sobre el Gobierno que debe responder, en todo momento, a la orientación política de la mayoría en las Cámaras $y$, en cierto modo, también a las minorias. Y, el negativo, en íntima relación con el anterior establece la pérdida de la confianza en que el Gobierno cumpla con las demandas de la mayoría de las Cámaras.

Por tanto, según los clásicos esquemas del parlamentarismo, la legitimidad del Gobierno es una legitimidad mediatiza, que se descompone en dos estadios: una legitimidad de origen de la que tiene que gozar el Ejecutivo en el preciso momento de su formación, ya sea con investidura formal o sin ella, y una legitimidad de ejercicio, pues el Gabinete está obligado a conservarla, como conjuro de su permanencia. De modo, que la confianza se tiene o se pierde y no hay punto medio en el que el Gabinete pueda descansar y coger impulso. 
A tal efecto, la lógica del régimen parlamentario niega, por propia definición, la igualdad entre sus distintos poderes, en la medida en que, el Parlamento es superior tanto funcional como institucionalmente. No obstante, en los tiempos actuales si hay algo que se reitera incasablemente en todo estudio, análisis, disertación o comentario sobre la institución parlamentaria es que en el mundo de los hechos la desigualdad entre ambos poderes se ha decantado en beneficio del Ejecutivo.

La relación fiduciaria propia de un sistema parlamentario de gobierno se materializa, en el caso español, en la forma de designación del Poder Ejecutivo por el Congreso de los Diputados, ex artículo $99 \mathrm{CE}$, lógica consecuencia de la posición preferente de esta Cámara en un sistema de bicameralismo imperfecto como es el español. En este precepto la Constitución española exige el indefectiblemente otorgamiento expreso de una confianza de la Cámara Baja antes de la definitiva formación del Gobierno.

En estos momentos en que se cumple el vigésimo quinto aniversario de nuestra Norma Fundamental merece hacer un repaso de la institución de la fiducia parlamentaria como institución viva. Las escasas referencias a la relación fiduciaria entre el Gobierno y las Cortes Generales, por lo general, se contienen en estudios sobre la responsabilidad política del Gobierno. Sin embargo, es posible analizar este instituto parlamentario autónomamente, pues si de algo deriva la responsabilidad política gubernamental es de una previa relación de confianza, que goza por tanto, de sustantividad suficiente para ser analizada como institución originaria.

La constitucionalización del trámite de la investidura fue una de las principales novedades de nuestra Norma Fundamental. El procedimiento que regula es singularmente complicado, dificultoso $y$, en ocasiones, insatisfactorio. En concreto el artículo $99 \mathrm{CE}$, ni ningún otro precepto de Nuestra Norma Fundamental, no exige que tras la exposición del programa por el candidato se deba celebrar un debate en el Congreso, algo consustancial a la lógica parlamentaria. Como consecuencia de la ausencia de prescripción expresa en la Constitución y en el Reglamento provisional del Congreso, en la sesión de investidura de Adolfo Suárez el 4 de marzo de 1979 no se celebró este debate, por no hablar del escaso rigor del discurso de investidura del candidato. Ante las reiteradas críticas, el actual Reglamento del Congreso de 1982 (art. 171.3) incluyó el carácter obligatorio de este debate, siguiendo el criterio de la Resolución de la Presidencia del Congreso de febrero de 1981 para la investidura de Calvo Sotelo de 25 de febrero de dicho año. 
Pero, además, el artículo 99 CE puede ser caracterizado de procedimiento original en el Derecho comparado, pues a pesar de las influencias recibidas de la Ley Fundamental de Bonn, no existe ningún referente. Esta circunstancia puede explicarse por las peculiaridades de nuestro periodo de transición política que determinó la convivencia un Parlamento democrático, resultante de las elecciones de 15 de junio de 1977, en contraste con un Gobierno no elegido parlamentariamente. Esto provocó numerosos problemas en las relaciones Ejecutivo-Legislativo que se dilataron como consecuencia del largo proceso de redacción de nuestra Norma fundamental².

El punto de inflexión que determinó la redacción vertiginosa de la Ley sobre Regulación Provisional de las Relaciones entre las Cortes y el Gobierno, a efectos de la moción de censura y de la cuestión de confianza de 17 de noviembre de 1977, fue el conocido "Caso Blanco", que terminó en la moción de censura de septiembre de $1977^{3}$.

Esto hizo que la referencia constitucional a las relaciones entre ambos órganos y, por ende, la exigencia de la confianza parlamenta-

2 La oposición, en contra del parecer de UCD que mantenia que la regulación de las relaciones Gobierno-Parlamento debía ser una cuestión de exclusiva regulación constitucional, sostenía la pretensión de que los Reglamentos Provisionales de ambas Cámaras regulasen la relación de confianza entre el Gobierno y las Cortes. Por ello, presentaron sendos votos particulares a los Informes de las Ponencias del Congreso y del Senado para la inclusión en ambos Reglamentos de la regulación correspondiente de los votos de confianza y censura. No obstante, estos votos particulares fueron derrotados.

3 El "Caso Blanco" tuvo su origen en la detención del diputado socialista Jaime Blanco por su participación en una manifestación preautonómomica en Santander. Su retención policial el 28 de agosto de 1977 instó la convocatoria del Pleno del Congreso el 13 de septiembre de 1977 y la formulación de una serie de mociones. Dos de ellas pedian expresamente la exigencia de responsabilidad política y la solicitud de cese del Ministro de Interior. Finalmente la moción de censura socialista fue derrotada por 118 votos a favor, 160 en contra y 58 abstenciones. Este hecho obligó al Gobierno a cambiar su posición inicial, presentando un Proyecto de ley de regulación de las relaciones Gobierno-Parlamento de fecha de 16 de septiembre, que fue finalmente aprobado por las Cámaras en tan sólo un mes y medio. Dicho Proyecto de ley señalaba en su Exposición de motivos "la necesidad de un cauce que sin prejuzgar las técnicas de control que definitivamente se adopten, permita vincular estrechamente el Gobierno a la mayoría de las Cortes haciendo posible a éstas expresar su confianza o censura respecto de aquél». El texto pretendía regular de forma provisional los trámites parlamentarios para la presentación de una moción de censura o una cuestión de confianza. Lo más curioso es que ambas formas de retirada de la confianza parlamentaria podían presentarse ante el Congreso y el Senado y que la censura podía dirigirse contra un Ministro de forma individual. 
ria fuese uno de los puntos centrales de nuestra Constitución, que la reguló de un modo muy diferente a lo contenido en la normativa provisional de 1977. La Ley provisional de 1977, no obstante, tenía como principal propósito el impedir, a través de una regulación embrollada y confusa, la exigencia de responsabilidad política en tanto en cuanto no se hubiese aprobado la Constitución. Además, no pretendía prejuzgar la futura regulación constitucional, aunque su espíritu fue seguido por el Texto de 1978.

En 1977, la composición de las Cámaras era de once partidos, cinco de ellos con más de diez escaños, es decir, un acusado sistema multipartidista que aumentaba la preocupación sobre la gobernabilidad de España, lo que podría influir peligrosamente en el asentamiento de un verdadero sentimiento de adhesión a la nueva Constitución. En aquellos momentos la formación de una robusta mayoría pasaba por la negociación con otras fuerzas políticas minoritarias. De aquí la complicada formulación del artículo $99 \mathrm{CE}$ y los obstáculos de la retirada parlamentaria de la fiducia a través de la moción de censura (art. 113). Ambos preceptos pretenden: por un lado, un reforzamiento del Poder Ejecutivo, $y$, por otro, garantizar la deseable estabilidad gubernamental, aunque ésta pudiera ser ficticia.

Nuestra Constitución es uno de las más fieles receptoras de los principios del parlamentarismo racionalizado ${ }^{4}$, pues el Texto de 1978 refleja en todo momento un acentuado temor a situaciones prolongadas de inestabilidad gubernamental. Se buscó a toda costa la formación de Gobierno, reduciendo incluso las mayorías para dar por otorgada la confianza.

Al margen de estas consideraciones, la originalidad de la regulación de la institución fiduciaria del Texto de 1978 se comprueba en dos notas. En la investidura únicamente se otorga la confianza al Presidente del Gobierno, que no está obligado a anunciar, aunque en alguna ocasión haya sido así, la composición del futuro Consejo de Minis-

4 El parlamentarismo "asilvestrado», si se permite la expresión, es decir, al margen de toda regla, fue el vigente hasta la primera guerra mundial. A partir de este momento comienzan a acogerse diferentes fórmulas que impidiesen la presentación de una censura en cualquier momento y bajo cualquier circunstancia. El ejemplo modélico de esta nueva tendencia es el artículo 67 de la Ley Fundamental de Bonn que, a su vez, tuvo como referente negativo una pésima regulación de la censura contenida en el artículo 49 de la Constitución francesa de 1946. De aquí surge la modalidad de la sfiducia constructiva hiperrracionalizada, ampliamente criticable. 
tros. Esto reafirma la posición del Presidente de verdadero director $y$ coordinador de la política del Poder Ejecutivo (art. $98 \mathrm{CE}$ ). Y, por último, a excepción de la Constitución portuguesa (art. 191) incluye expresa mención del "programa político del Gobierno", a pesar de que éste no parezca ser más que una mera declaración de intenciones.

Posteriormente la práctica cotidiana ha aportado la segunda característica de nuestro sistema: la preeminencia del Poder Ejecutivo. Sin duda es así, pues todas las crisis de Gobierno que han tenido lugar en los veinticinco años de vigencia de la Constitución de 1978 han sido provocadas y solventadas fuera de las paredes del Congreso de los Diputados.

Desde estos parámetros, la relación fiduciaria Gobierno-Parlamento es una de las instituciones de nuestra Constitución más férreas, no en sí misma, sino gracias a cómo ha sido arropada por el Texto de 1978. Primeramente, porque nuestro Texto constitucional exige que se formalice de modo expreso. En segundo lugar, porque sin el número de votos necesarios en la primera votación de la investidura, previos los pactos de gobierno que se quieran, no hay posibilidades de formar Gobierno, mejor dicho los partidos políticos se resistirán a gobernar en minoria. Pero además, los múltiples frenos y obstáculos que nuestra Norma impone al Congreso en la exigencia de responsabilidad política arrojan la desalentadora conclusión de que, una vez formado Gobierno, es prácticamente imposible retirarle la confianza.

La solicitud de la confianza sigue siendo el punto central de nuestro sistema de gobierno; un acontecimiento de singular relevancia jurídico-constitucional al que la Constitución otorga por sí solo una virtualidad destacada capaz de restar capacidad a la función de control del Gobierno. Una vez concedida por el/los Grupos parlamentario/s, si fuese necesario pacto de Legislatura, se crea en favor del Ejecutivo una perpetua confianza parlamentaria, a modo de presunción inquebrantable, que despliega todos sus efectos desvirtuando toda iniciativa de cualquier fuerza política con representación en el Congreso. Sólo como instrumento al servicio de esta presunción se explica esa peculiar combinación de mayorías parlamentarias que exige mayoria simple para entender revalidada la confianza, pero impone mayoría absoluta para derribarlo mediante el ejercicio de la censura.

El diseño constitucional español se presenta tendencialmente proclive a blindar al Ejecutivo, a pesar de que la práctica política en estos veinticinco años haya impuesto que la relación fiduciaria en el momento inicial se traduzca en un número significativo de escaños (176). La contrapartida son unas Cámaras atadas de pies y manos una 
vez que han otorgado la confianza, y ni siquiera eso, porque el trámite del otorgamiento de la fiducia es monopolizado por el Grupo parlamentario afín al candidato a la Presidencia que hubiese obtenido el mayor número de votos. Es la oposición la que no tiene posibilidades reales de participación en la conformación de la línea política de Gobierno.

Partiendo de esta descripción parece inevitable una reformulación de una relación fiduciaria, que ésta parece haber perdido toda valencia política desde los esquemas clásicos. Si la investidura se reduce a un mero recuento de los escaños obtenidos por el partido político más votado, si la moción de censura y la cuestión de confianza son instrumentos supeditados hoy en día a la lógica imparable de las mayorías, y si el convencimiento liberal de que el Parlamento es órgano de gobierno de la Nación se ve reducido a la formalización de unas decisiones de gobierno tomadas fuera de sus paredes, habrá que concluir que hace tiempo que asistimos a los solemnes funerales del sistema parlamentario. Además, mientras en el parlamentarismo clásico la institución de la fiducia operó como verdadero mecanismo legitimador de un Ejecutivo subordinado al Parlamento, hoy en dia el Gobierno goza de otras vías de legitimación diferentes de la clásica fiducia. En la actualidad parte de la doctrina constitucional se muestra proclive a rebatir la ausencia de legitimidad del Gobierno, pues entienden que ésta se otorga por otras vías, al margen de la confianza parlamentaria. Las elecciones generales habrían dejado de ser exclusivamente un sistema de elección del Parlamento, para pasar a ser consideradas una forma de nombramiento del Presidente, es decir, el candidato más votado tiene una legitimidad democrática bastante diáfana.

El lugar central del juego político ha pasado a ser ocupado por el trámite de la "conformación de la mayoria necesaria» si las urnas no lo hubiesen dejado previamente establecido. En estos casos, apunta Duverger, es como si el pueblo cada cuatro o cinco años fuese invitado a repartir las cartas entre jugadores entre los que no puede escoger y para un juego del que permanecerá excluido (La VI Republique et le régime presidentiel, pág. 59). El Congreso tiene la obligación de poner en marcha la maquinaria institucional conformando y redondeando esa mayoría en torno al líder más votado. No es tan sólo una legítima aspiración del constituyente, sino que, a la vista de los acontecimientos en la Asamblea de la Comunidad Autónoma de Madrid, empieza a ser defendido a capa y espada como una obligación cuasijurídica de los partidos políticos con representación parlamentaria. De este modo, la relación fiduciaria despliega su eficacia hacia el interior 
del Estado desde el momento en que impone y exige el acuerdo entre las fuerzas políticas con representación parlamentaria, pues de ellos depende el funcionamiento del sistema. Si esto no se consiguiese, parece no quedar otra alternativa que una nueva consulta al cuerpo electoral.

Estamos ante una mayoría preconstituida $y$, en consecuencia, ante una fiducia preconfigurada. El Parlamento interviene para ratificar una relación fiduciaria madurada antes de la constitución del Congreso y fuera de él, o bien debe desbloquear una posible situación de inmovilidad institucional mediante la convocatoria de nuevas elecciones pasados dos meses sin solución de continuidad.

Frecuentemente los nuevos derroteros por los que han transcurrido los modernos sistemas parlamentarios encuentran una explicación en la influencia del sistema de partidos. Desde la irrupción de los partidos de masas parece haberse consolidado una tendencia que ahora se muestra tendenciosamente lesiva de la posición del Parlamento. La influencia del "Estado de partidos", denominación que se inmortalizó en España con el conocido estudio de García Pelayo, ha extendido la idea de que la relación fiduciaria se asemeja más a un vínculo meramente formal entre el Gobierno y una mayoría parlamentaria, que estarían igualmente vinculados aun $\sin$ la existencia de ésta.

Una democracia representativa necesita del reconocimiento tanto expreso como real de fuerzas sociales y políticas. Este pluralismo desde hace tiempo se canaliza a través de los partidos políticos que para algunos tomaron al asalto el Parlamento, e incluso se instalaron en el interior de la organización del Estado. Pero sería una superchería afirmar que el sistema de partidos es la madre de todos los males de la institución parlamentaria. Negar su papel en los sistemas democráticos parece algo hipócrita. A día de hoy, los partidos políticos son la forma en que se canalizan las diferentes opciones políticas de una comunidad de intereses. Por lo menos no hay forma conocida que tengan posibilidades de desterrarlos del mundo político.

Se quiera o no a través de ellos se formaliza aquella voluntad general de estirpe rousseauniana, y no vale decir que por encima de los intereses sociales que representan está el sistema parlamentario, porque éste es precisamente una fórmula de gobierno que preconiza la superioridad del Parlamento como máxima institución representativa en tanto en cuanto el debate y la discusión en su seno es el método más racional con el que conocer la voluntad general. 
En realidad, casi desde el principio fue así. La afilada pluma de Adolfo Posada ya lo ponía de manifiesto en tiempos de la Restauración: "el Parlamento está llamado a recoger las corrientes de opinión pública, a condensarlas, para lo cual le sirven como vehículos conductores el sufragio en el ejercicio, las reuniones públicas, la prensa y los partidos. Véase sino que ocurre en Inglaterra. Prescindiendo de los defectos que como toda institución humana tiene allí el Parlamento (...), no puede negarse que la campaña electoral es una verdadera manifestación de la opinión pública, que la prensa refleja las necesidades diarias de esta opinión, que los partidos la conducen y que el parlamento, en relación constante con ella, por virtud de la costumbre que los grandes políticos suelen tener de dar cuenta de la gestión política a sus electores, refleja el estado general de la misma" (pág. $60)$.

La vieja disyuntiva entre gobierno representativo y democracia parlamentaria, que precisamente está en la base de las diferencias entre formas de gobierno, dejaría de tener sentido. Limitación del Poder Ejecutivo y reconocimiento del pluralismo político a través de los partidos no debería ser incompatible.

El problema está no en la existencia de partidos políticos sino en la lucha por el poder; en la competición entre éstos que termina por radicalizar posiciones $y$ atrincherar a cada uno de los sujetos en contienda en posiciones irreconciliables. Los electores responden a dicha dinámica de enfrentamiento convirtiéndose en acérrimos seguidores de un partido. $Y$ de igual modo el diputado deja de ser un parlamentario individual. Para tener posibilidades reales debe ser seleccionado por los órganos de dirección del partido y ocupar un puesto cercano a los primeros de la lista. Esto crea una situación de dependencia y disciplina elegible-partido, que termina por configurar un mapa de Mayoría-Minorías a modo de fórmula con que se traduce, aunque no del todo, el influjo socio-político de una ideología, o tal vez, ni tan siquiera eso. En palabras de García Pelayo "mayoría y minorías no son el resultado de votos libres e iguales, sino expresiones del mayor o menor influjo de cada partido" (pág. 33).

Esto es lo que verdaderamente distorsiona la relación fiduciaria clásica y no la existencia de partidos políticos. Lo preocupante es que el Derecho Constitucional, anclado en unos planteamientos demasiado liberales para los tiempos que corren, no se ha adaptado a estas exigencias y en ocasiones parece seguir considerando al fenómeno como una abstracción; como algo ajeno a la dinámica parlamentaria. 
El contraste entre la constitucionalización de la relación fiduciaria y la ausencia de referencias a los partidos políticos en los Títulos IV yV de la Constitución demuestra este alejamiento, al margen claro está del artículo $6 \mathrm{CE}$, por mucho que el artículo 99 CE hable de «Grupos políticos con representación parlamentaria».

Ignorar que el parlamentario llega a serlo por su fidelidad a una opción política no conduce a nada, porque ello es difícilmente superable en términos generales y no basta con gritar al viento que el Diputado debe obedecer a criterios de rectitud ética y convicciones personales. Su futuro político depende de que su actitud no sea vista por el partido como desleal. Además, los partidos funcionan como organizaciones fuertemente jerarquizadas, sometidas a una disciplina interna y con pleno sometimiento a la línea política que determine su líder. Si no es así no son percibidos por la opinión pública como una opción seria de gobierno, o, al menos, ésta parece ser la convicción que se ha instalado en el subconsciente del elector.

Por tanto, en sistemas parlamentarios mayoritarios las elecciones son una selección cuasi-directa del Ejecutivo, que en el trámite de la investidura institucionaliza la figura del líder del partido. Es poco probable que la mayoría parlamentaria no se identifique con el Ejecutivo. Lo que no parece tan improbable es que no se puedan producir escisiones en las filas de la mayoría.

El artículo 99 CE impide la conformación del Ejecutivo sin la previa comprobación del ligamen fiduciario, es decir, sin la operación aritmética de que efectivamente cuenta con una mayoría clara, cohesionada, permanente, una mayoría de Legislatura, determinada y determinable. Esto es aún más claro cuando las urnas no han conformado con claridad dicha mayoría. En estos casos, la investidura vuelve a adquirir toda su virtualidad, mejor dicho, su potencial carácter de verdadera pieza maestra del régimen parlamentario. Tal vez sea el modo más adecuado de explicar en los años sucesivos la moción de investidura que preceptúa nuestro Texto constitucional.

Esta nueva forma de entender el parlamentarismo puede ser atacado por considerarlo minusvalorante. Pero, aun admitiendo esta crítica, al Parlamento siempre le quedará su condición de órgano constitucional especialmente apto para dar vida al mecanismo procedimental de designación del Gobierno, dada su probada tradición representativa. Además, nuestro Tribunal Constitucional en su Sentencia 141/1990, de 20 de septiembre (F.j. 4. ${ }^{\circ}$ ), reiterando la STC 16/1984 (F.j. $6 . \%$, recuerda que el modelo parlamentario no debe ser considerado como una mera técnica de elección del Presidente sino que se inserta 
en un orden de valores y principios constitucionales a los que sirve $y$ ha de inspirar la interpretación de las normas que lo regulan. El predominio del Gobierno no tiene porqué conducir inexorablemente a una inoperancia del Parlamento, pues esta tesis de la ineficacia o incluso invalidez de la forma parlamentaria de gobierno debería desembocar en reiteradas propuestas de sustitución por el régimen presidencial. $Y$ sin embargo, curiosamente o no las ha habido o han sido tan sigilosas que se han volatilizado inmediatamente.

Sin embargo, no todos los sistemas parlamentarios son mayoritarios, por lo que estas conclusiones deben ser recibidas con cautela, ya que siempre debe tenerse presente la gran dificultad de precisar todas estas cuestiones. Con la confianza parlamentaria, como con el sistema parlamentario en general, no pueden darse conclusiones fijas porque el resultado final dependerá siempre de una previa consulta popular, del momento político de que se trate y de los avatares propios de la vida parlamentaria. Probablemente el ensayo clínico que se realizase nunca sería ratificado por los resultados posteriores. Como decia Winston Churchill: "Logic ... has proved fatal to parliamentary government».

Lo que sí parece difícilmente refutable es que una vez materializada la relación fiduciaria, ésta está llamada a dormir un dulce letargo durante toda la Legislatura, pues aquí sí ha perdido todo su poder. El sistema parlamentario español podría ser caracterizado como un "parlamentarismo exclusivamente positivo" o "parlamentarismo en origen", o mejor dicho, "parlamentarismo de relación fiduciaria en origen", pues una vez comenzada la Legislatura la confianza deja de sentirse. La relación fiduciaria se disocia en la práctica parlamentaria en tres momentos: conformación de la mayoría, votación de investidura y validación formal de los apoyos parlamentarios a la vista de los resultados electorales, y comprobación permanente de que se sigue contando con dicha confianza. Este tercer elemento ha perdido toda su valencia política. Ni siquiera la institucionalización, vía consetudinaria, del Debate sobre el estado de la Nación ha conseguido la revitalización de la relación fiduciaria. Curiosamente uno de los efectos del Debate sobre el estado de la Nación ha sido el fortalecimiento del Presidente del Gobierno (De Esteban y González-Trevijano, Curso de Derecho Constitucional español, pág. 603). Concedida la confianza, ésta subsiste hasta el final de los cuatro años de mandato, a menos que se muestre una actitud abiertamente hostil a la politica gubernamental.

El programa político, que el Presidente del Gobierno expone en el momento de la investidura, condiciona la actividad del Gobierno a 
lo largo de su mandato. En caso de desacuerdo el Parlamento puede obligar al Ejecutivo a presentar su dimisión, la cual se produce fundamentalmente a través de dos mecanismos bien delimitados: la cuestión de confianza y la moción de censura.

Así entendida, la responsabilidad política del Gobierno es el propio corazón del régimen parlamentario, su verdadero elemento «indefectible" (Elia, pág. 642), esto es, su elemento esencial (Duverger, Instituciones..., pág. 142), su contenido mínimo indispensable (Pérez Royo, pag 92), la espada de Damocles que cuelga sobre cualquier Gobierno, a no ser que posea una mayoría tan segura que le permita superar cualquier tormenta (Loewenstein, pág. 263), aunque nuestra vigente Constitución refuerce de tal modo al Poder Ejecutivo que impida que el Parlamento le exija siquiera atisbos de responsabilidad política. La Constitución se esfuerza por facilitar la formación del Gobierno, así lo demuestran las múltiples posibilidades que sanciona el artículo $99 \mathrm{CE}$, en cambio dificulta su cese. Ello naturalmente influye en la institución de la fiducia parlamentaria.

La responsabilidad política ya no es eficaz en los regímenes parlamentarios. Hoy en día, el Parlamento no controla al Gobierno, entendiendo que ambos son dos entidades separadas. Lo que se opone al Gobierno no es el Parlamento, sino una posición minoritaria y con escasísimas posibilidades. Ya no tiene sentido hablar del sistema parlamentario como sistema en que el Legislativo se sitúa frente al Ejecutivo y abandera una situación de permanente lucha contra un Gobierno que debe ser vigilado permanentemente.

La dinámica parlamentaria de finales del siglo $X X$ y principios de XXI está cambiando, ello es indudable. El modo en que articulan las relaciones Gobierno-Parlamento, ya no obedece a una situación de enfrentamiento dialéctico y funcional, sino de una coordinación orgánica, que incluso obliga a revisar los esquemas clásicos sobre la división de poderes. Ejecutivo y Legislativo han dejado de ser dos poderes separados por una línea divisoria fácilmente determinable. A lo largo de la Legislatura son dos órganos constitucionales que cooperan gracias al nexo del único Grupo parlamentario otorgador de "su» confianza.

No es necesario volver a relatar cuáles son los trámites constitucionales para poder presentar una moción de censura y en qué modo el núcleo básico de la relación fiduciara se sobreprotege, todo ello es de sobra conocido. Baste decir que dado el actual sistema de partidos, la forma en que se desarrolla la vida parlamentaria y el proceso de toma de decisiones monopolizado por el principio de mayorías, la 
moción de censura no puede ser entendida más que como una especie de hara-kiri colectivo ciertamente surrealista (Avril, pág. 398). Refleja un deseo irrealizable, una operación infructuosa, una especie de aspiración absolutamente legítima pero impracticable.

Una moción de este tipo sólo es útil como medio para desgastar al equipo gubernamental o para descalificarle ante la opinión pública. Aunque en los últimos meses ha quedado demostrado que para este viaje no hacen falta estas alforjas. Ni siquiera en la sonada crisis del Prestige la oposición era partidaria de presentar la censura y así lo descartó en cuanto sonaron las primeras voces. Si la censura no iba a tener ningún efecto institucional, para proclamar la ineptitud política del Gobierno, la oposición contaba con la amplia repercusión que la tragedia ecológica tuvo en los medios de comunicación.

A la crítica parlamentaria ni siquiera le sirve la censura. El coste político para la oposición si su discurso no logra conectar con el electorado puede ser muy elevado. Podría incluso tener un indeseable efecto boomerang.

En realidad, la caída de un Presidente en la democracia española será una trabajo costosísimo. Una especie de David contra Goliat, que producirá tal desgaste en la oposición, que incluso podría situarla en una situación de desventaja frente al partido en el poder. Es posible que en esta lucha, la oposición cometa algún error que será magnificado por un Gobierno en actitud defensiva, $y$ al final el elector indeciso no sabrá a que carta quedarse o, incluso, llegue a pensar que el partido instigador no es una alternativa política convincente.

La dimisión de un Gobierno es una especie de "inconocible», de acontecimiento singularísimo, pero que en ningún caso responderá a los corsés jurídicos con los que se quiso establecer cierto orden en la vida política. Basten como botón de muestra los ejemplos de nuestra historia reciente.

La moción de censura presentada en tan solo año y medio de ser aprobada la Constitución evidenció como los proponentes no pretendian derribar al entonces Presidente, sino concentrar el interés de la opinión pública en la supuesta ineficacia del Gobierno, y con ello catapultar a Felipe González a la Presidencia. Los objetivos que perseguían los proponentes no eran jurídicos, sino políticos. Los socialistas buscaban fundamentalmente mostrar a la opinión pública los fallos del Gobierno y dar a conocer las propuestas socialistas para las siguientes elecciones. Iguales eran los motivos en 1987. Se con- 
cibió como una forma eficaz para que un desconocido Hernández Mancha pudiera exponer sus propuestas políticas en el Congreso de los Diputados.

Ambas evidenciaron que la moción de censura ha dejado de ser un instrumento primigenio de exigencia de responsabilidad política. Una cuestión de confianza o una moción de censura ni siquiera alumbran una eventual dimisión voluntaria del Presidente del Gobierno. A lo sumo podrá hablarse de una responsabilidad política difusa, pero entonces la confianza no la retira el Parlamento, sino el cuerpo electoral que no revalida la elección con su voto negativo en las urnas. $Y$ lo curioso es que, según los esquemas del parlamentarismo clásico, sólo se puede ser responsable frente a quien otorgó la confianza, es decir, frente al Parlamento. Así, el Presidente debería ser responsable ante el Congreso de los Diputados y los miembros de éste frente a sus electores. No existe responsabilidad frente a quien no ha depositado ninguna confianza.

La responsabilidad política parece no haber podido resistirse a un proceso evolutivo, patente a partir de la segunda mitad del siglo $X X$, que afecta a la misma esencia del concepto jurídico-constitucional de responsabilidad. Bajo la presión de una opinión pública más exigente, la búsqueda de los responsables y de las vías por las que efectivamente asuman esa responsabilidad se ha hecho cada vez más viva en el mundo político, porque la sanción política se ha convertido en inexistente. Bustos Gisbert en una interesante monografía sobre las posibilidades reales de la responsabilidad política en el parlamentarismo racionalizado (La responsabilidad política del Gobierno ¿realidad o ficción? La necesaria reformulación de un principio esencial del sistema parlamentario, pág. 18) señala que ues hoy inaceptable a la luz de la realidad política especialmente en las formas de gobierno parlamentarias con el predominio del principio de canciller y con mayoría parlamentarias de un solo partido. Y éste a nadie se le oculta es el caso de la forma parlamentaria de gobierno español». Tal vez la forma en que transcurrirá la exigencia de responsabilidad política en los años sucesivos, pase por potenciar fórmulas de "responsabilidad menor", que por obra del principio de solidaridad convenientemente actuado, podría incluso, en determinadas circunstancias, romper el ligamen fiduciario, aunque las fórmulas utilizadas hasta la fecha, las mociones individuales de reprobación no lo hayan conseguido del todo. No obstante, es posible que en un futuro pudiera adquirir cierta juridicidad por vía de su consideración como costumbre parlamentaria o, incluso, convención constitucional. 
Ahora bien, la ruptura del vínculo fiduciario no se realizará de un modo expreso, pues "la responsabilidad política entendida como procedimiento de rendición de cuentas, excede en su funcionamiento de los esquemas de análisis exclusivamente jurídicos aunque se manifiesten a través de instrumentos regulados jurídicamente» (Bustos Gisbert, pág. 108). Se pueden rendir cuentas de modos muy diversos $y$ no sólo con la dimisión. No sería difícil argumentar que dimitir, salvo en escándalos de corrupción política o favoritismo, no es una verdadera respuesta a las críticas sobre determinada gestión política, sino dejar el camino expedito para que otro encauce esa defectuosa gestión. Responder políticamente también puede ser la reconducción de una política insatisfactoria por aquél que recibe las críticas.

Los actuales gobiernos parlamentarios parecen ir adaptándose a esta nueva forma de entender la responsabilidad política ante el riesgo de perder parte de un electorado probablemente decisivo en las siguientes elecciones generales. Otra cosa es que no estemos ante supuestos de exclusiva responsabilidad política, pues cuando la conducta tenga visos de criminalidad la sociedad los enmarcará entre las transgresiones que merecen el más alto reproche social y la máxima pena criminal.

\section{BIBLIOGRAFÍA}

AVRIL, O., "Trois remarques á propos dès requisitions du Ministére Public dans l'affaire du sang contaminé», Revue du Droit Public et de Science Politique en France et a l'Étrangère, n. ${ }^{\circ} 2,1999$.

Bagehot, W., The English Constitution, World's Classic, Londres, 1955.

Bustos GisBert, R., La responsabilidad política del Gobierno ¿realidad o ficción? La necesaria reformulación de un principio esencial del sistema parlamentario, Colex, Madrid, 2001.

Carré de Malberg, R., Contribution a la Théorie Générale de l'État, vol. II, Sirey, París, 1922.

De Esteban, J., y González Trevijano, P., Curso de Derecho Constitucional español, t. III, Servicio de Publicaciones de la Facultad de Derecho. UCM, Madrid, 1994.

De Secondat, Ch., Barón de Montesouieu, Del espíritu de las Leyes, trad. M. Blázquez y P. De Vega García, Tecnos, Madrid, 1998.

Duguit, L., Traité de Droit constitutionnel, vol. Il., Ancienne Libraire Fontemoing, París, 1928. 
DUVerger, M., Instituciones Políticas y Derecho Constitucional, traducción Aja, E.; Aparicio, M. A.; Arbós, X.; Carrillo, M.; Gerpe, M.; Molas, I.; Oller, D.; Sólé.Tura, I., y Vallés, J. M., Ariel, Barcelona, 1980.

- La VI Republique et le régime presidentiel, Fayard, París, 1961.

ELIA, L., "Governo (forme di)", en Enciclopedia del Diritto, voL XIX, Giuffré, Milán.

García Pelayo, M., El Estado de partidos, Alianza Editorial, Madrid, 1986.

González Trevijano, P., La cuestión de confianza, McGraw Hill, Madrid, 1996.

Hauriou, M., Principios de Derecho Público y Constitucional, traducción Carlos Ruiz del Castillo, Reus, 2. ${ }^{a}$ ed., Madrid, 1927.

Loewenstein, K., Teoría de la Constitución, trad. A. Gallego Anabitarte, Ariel, Barcelona, 1970.

Pérez Royo, J., Curso de Derecho Constitucional, Marcial Pons, Barcelona, 1998.

Posada, A., Estudios sobre el régimen parlamentario en España, estudio preliminar de Francisco Rubio LLorente, Junta General del Principado de Asturias, Oviedo, 1996.

ReVEnga González, M., La formación del Gobierno en la Constitución española de 1978, Centro de Estudios Constitucionales, Madrid, 1988.

ScHmitT, C., Sobre el parlamentarismo, trad. Thues Nelson y Rosa Grueso, Tecnos, Madrid, 1990.

SÁnChez Agesta, L., El sistema político de la Constitución española de 1978, 3. ${ }^{a}$ ed., Ed. Nacional, Madrid, 1984. 